\title{
Leprosy Education in the Villages
}

\author{
R. VEDABODAKAM, L.M.P. \\ Medical Officer, St. Luke's Leprosarium, Tirunelveli Dist., India.
}

Effective leprosy control must rest upon accurate survey work, and upon a system of follow up and tracing of defaulters. In practice many schemes began with a survey of the control area by paramedical workers. Ideally this continues with the administration of drugs and follow up by paramedical workers under the general direction of the doctor, and in many units propaganda is conducted as opportunity and means permit. An ideal scheme is naturally costly in terms of personnel and money, and is beyond the scope of small general medical units in areas where leprosy happens to be endemic.

St. Luke's Hospital, Nazareth, is such a unit. It is a Christian hospital of $\mathrm{I} 20$ beds, completely staffed by nationals, and deriving no financial help from the diocese, the state, nor from overseas. The leprosy problem of the surrounding district came to our notice in the following way. Six patients from the village of Peikulam attended the outpatient clinic at St. Luke's. This involved walking a distance of over 22 miles in hot sun at a time when drought and near famine prevailed. Nevertheless their condition began to improve. Suddenly they stopped attending, and in order to obtain information about them we went to their village which we had never visited before. We found them famished, with blistered feet, and in a distressed condition from the long walks in the tropical sun. Their plight suggested an immediate sample survey of the locality. This was undertaken, and revealed a tragic situation. In a village of 86 houses there were 42 leprosy patients, men, women, and children. A nearby village with 82 houses had 36 patients; a small school with 40 children had nine; another with I 20 had I3. A hamlet of I I houses had nine heavily infected patients.

The presence of so many leprosy patients in such a small area immediately suggested the need for a local treatment centre. Twice a week we visited the infected villages and attempted to distribute sulphone tablets from stands under convenient trees. Swarms of patients gathered to receive the tablets, but to our surprise, the villagers chased us from place to place, fearing that these groups of patients would import the disease into their own village. Eventually we approached the Collector of the district who allocated an area of land just outside the village of Peikulam for our use, and here has grown up a unit with accommodation for 48 inpatients, and with rehabilitation activities based upon two acres of land with a well, oil engine and pump set. With assistance from American Leprosy Missions and the British Leprosy Relief Association expansion is continuing, with influential people of the district lending their support.

Although it has become our aim to eradicate leprosy from the endemic area, it became quite clear that a thorough survey and epidemiology programme based upon paramedical workers was beyond the means of St. Luke's. Nevertheless we felt that we might reach out to the villages by means of systematic propaganda and educational work, and that this might in some measure take the place of survey work. The illiteracy of the remote villages presented an obstacle, and drove us to improvise our own method of portraying the basic scientific truths of this complicated disease.

The real problem was not that of the beggars, but of those lakhs (lakh $=$ I oo,ooo) of patients who have neither discovered their disease nor been recognised by society. There are also those who suspect their condition but conceal the evidence because they are afraid that society will ostracise them as soon as they become known as leprosy subjects. The public and many patients still do not know that there are cheap and effective drugs available, and they do not know that with these drugs early patients can be cured before they develop deformity. Wide publicity for these facts was needed in our area in a form readily understood by the villager. We felt that our project would only be possible 
if every resident of the villages was reached, both patient and unaffected persons; we felt that the entire population of each village would have to be given the knowledge of leprosy before we could succeed in our plan, which is the eradication of leprosy from the endemic area. It is our purpose in this paper to describe the effects of a simple educative propaganda venture upon the response of the villagers to antileprosy work in a highly endemic area.

The Educative Programme:

Initially this took the form of a ten minute talk before starting the clinic on outpatient days at Peikulam. Later we felt that this was only touching the fringe of the problem and was not reaching the hidden cases in the villages. Thus the form of propaganda now in use was devised, and has now been carried out regularly for the past 3 years in the remote corners of this area of endemicity.

Our aim was to reach every member of the village with our propaganda. We included the healthy members in the hope that social ostracism would afterwards be rejected by their minds. We regarded the education of the healthy residents as a decisive factor in encouraging the concealed patients to come out into the open for treatment. Social ostracism is perhaps the major obstruction to our effort to clean up the area, and our propaganda contains much material aimed at the healthy individual. This material emphasises the relatively rapid cure of early cases and the importance of inducing them to come forward for treatment. Without the co-operation of the uninfected we felt that our attempts at leprosy control would prove largely fruitless. It was something of a challenge

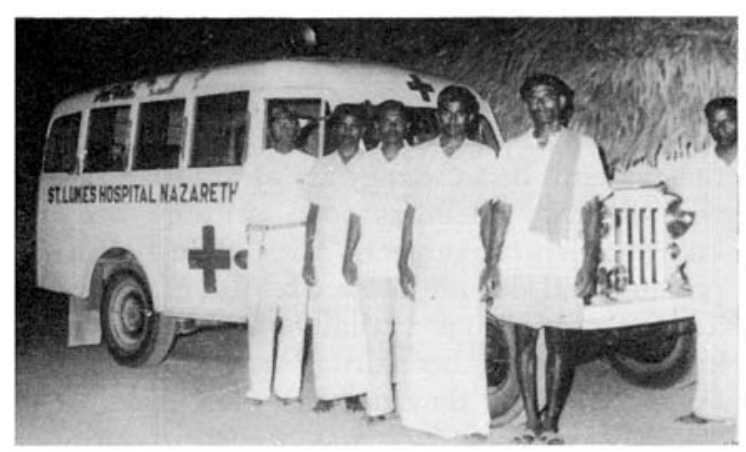

FIG I The team with ambulance fitted with loud speaker. to capture the interest of the healthy villager and to convert it into fascination and cooperation.

\section{Presentation of the Propaganda Programme:}

This can be varied to suit local conditions, but the method which we found to be acceptable in the villages of South India is as follows:

The village is selected, and a week in advance the President of the Panchayat is informed of the proposed visit. The news is circulated and the village becomes expectant. We arrive in the village at 6.00 p.m. (Sunday) in our ambulance fitted with loudspeaker and gramophone, run off the van battery. First we contact the Panchayat President (Panchayat $=$ Village Council) and request him to preside at the function. The ambulance tours in the village relaying music and announcing who we are, the purpose of our visit, and extending a warm invitation to everybody to attend the lecture and see the pictures. The meeting convenes at a spot chosen by the President, the programme opening with a few selections of classical music. Meanwhile the doctor and his assistants take a stroll through the streets to acquaint themselves with the atmosphere and status of the village, and the general capacity of the people to understand the subject to be presented. It is now 7.30 p.m. and the whole village has usually mustered at the meeting place. The magic lantern and the screen are set in position. A kerosene Petromax lamp first provides light for the audience and lecturer, and then is put into the lantern to project the pictures onto the screen. Thus one kerosene lamp serves both purposes, there usually being no street lighting in the village.

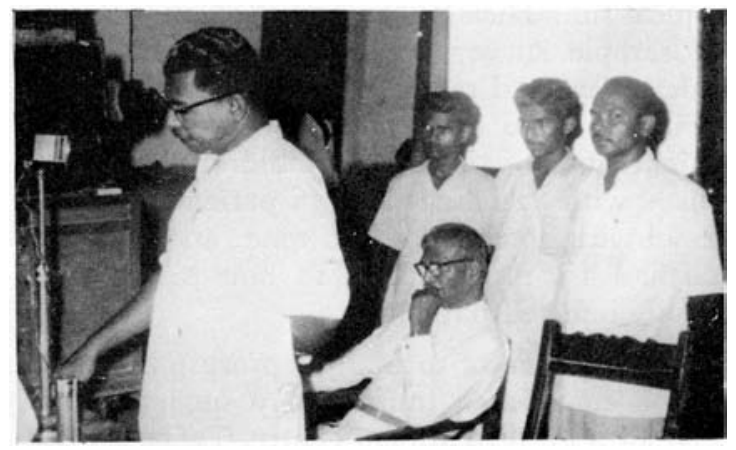

FIG 2 The Panchayat President introduces the subject and the speaker. 


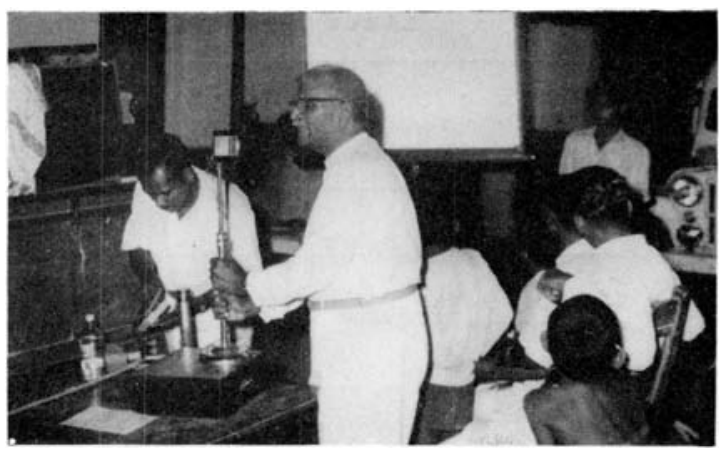

FIG 3 With lantern and screen in position the doctor begins the lecture.

The chairman introduces us and the subject we have come to present as the one most urgently needed to help the infected village. Soon rapt attention prevails. The lecture is delivered in homely language illustrated with simple analogies in such a way as to arrest the audience's attention. The material contained in the lecture may be briefly stated as follows.

\section{Synopsis of the Lecture.}

Leprosy is a social menace. Untreated it ruins individuals insidiously, and ravages families, communities, and the nation. It is not a respector of persons. The ratio of recognised to unrecognised cases is $\mathrm{I}: 8$. The disease is caused by the leprosy bacillus which attacks mostly skin and nerves. Mode of infection: Repeated contact with infected people and material, especially an infected close relation. What are the nerves? Nerves illustrated by reference to the head telegraph office in the state capital and its relation to small telegraph office (some local offices can be mentioned) by wires. So also is the brain related to the fingers and toes through sensory and motor nerves. When these minute nerves are attacked by leprosy germs sensation is first affected, and later movements. First signs: Invariably an anaesthetic patch since the minute nerve fibres underneath have been attacked by the germs, as exemplified by white ants eating the roots of grass, rendering it white. Insidiously the patch develops, becoming two or more patches in the course of months. After a year or so a bent finger develops, and later other deformities which can be recognised, shunned, and ostracised by all. An untreated leprosy subject in a village may disseminate the

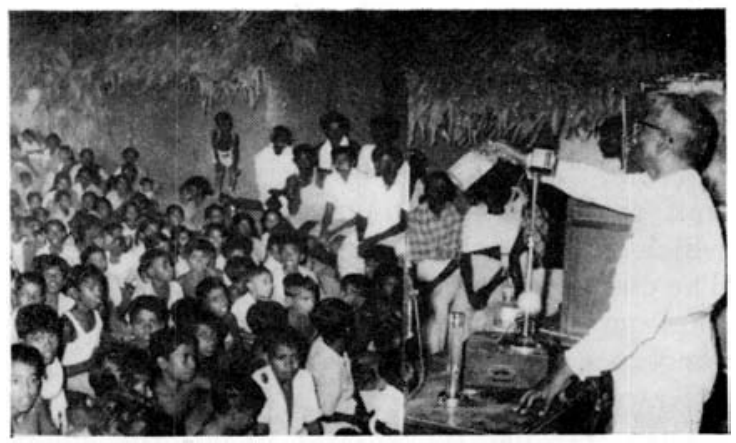

FIG 4 A section of the audience; the speaker demonstrating a specimen to illustrate a point.

infection unwittingly to others. He may be an unrecognised source of danger, but he cannot be driven out because he is by right a citizen. But with regular treatment he shakes off the germs slowly but surely and after a time he becomes negative. Though deformed such 'burnt out' patients are no longer a danger to home or society as they are devoid of the germs in their bodies. Therefore insist that all cases take treatment in their own interests as well as those of their families and society at large. Prevention: Voluntary segregation at home under regular treatment soon enables the patient to become negative and to take his rightful place in the home and society. Though deformity may persist after he is declared negative, he ceases to be a danger to society as a result of his cooperation with the doctor.

The poor patient cannot heartlessly be thrown out of the village; on the other hand he should become the concern of the whole village lest he spread the infection by wandering about uncared for and without treatment. The village should act not by coercion but by love and concern for the poor brother. The village Panchayat should provide for him a separate hut with bed and clothing. From the Panchayat funds food should be supplied to the patient and his household, and the village should see that he takes treatment regularly from the clinic. Thus the disease binds the sufferer to the hearts of the villagers, and they demonstrate their rejection of ostracism in a practical manner. Cost of treatment: The cheapness of treatment is strongly emphasised, plus the fact that it is available free to all living in the endemic area. 
Thus none can excuse themselves on the grounds of poverty. The efficacy of treatment is stressed, and numerous medical and surgical cures are portrayed on the screen.

While the lecture is proceeding some of the staff go round the streets putting up posters which reinforce the facts stated by the lecturer. The posters are intended to be seen the following morning as the villagers go to work. The lecture concludes with the announcement that booklets are available about leprosy at a nominal price $(25 \mathrm{nP})$. We like the villager to pay this small sum so that he values the literature. Thus the lecture ends, and after the chairman's closing remarks, the meeting closes with the national anthem from the ambulance gramophone. The lecture with pictures has taken an hour and a half, and it is now 9.oo p.m.

Results: It is naturally difficult to assess objectively the effects of these lectures. The results of a changed attitude towards leprosy takes time to manifest itself, and the incidents which spring from it occur out of sight of the workers. 77 villages have been visited in the past two and a half years, and all have given a full and sympathetic hearing. Even without the help of psychologists and social workers we have been able to detect some evidence of the effects of the visits. Regularly, immediately after the lecture additional cases from the visited village appear at the next outpatient clinic at Peikulam (Table I). Some of these recognise the disease themselves as a result of what they have heard, others are sent by the heads of families for similar reasons. Some say that the healthy neighbours urged them to take treatment.

A parish priest has observed that ulcers on the hands of many of his parishioners have disappeared. Itinerant cases are directed by villagers to the leprosarium, and influential people are taking interest in the work. Occasional detailed surveys some weeks after a lecture have mostly shown that all the cases of the village have come forward and are receiving treatment.
T A B L E 1

\begin{tabular}{|c|c|c|}
\hline Village & $\begin{array}{l}\text { No. of known cases in the } \\
\text { village before the lecture }\end{array}$ & $\begin{array}{l}\text { No. of addiiional cases } \\
\text { presenting as a result of } \\
\text { the lecture }\end{array}$ \\
\hline A. & 16 & 30 \\
\hline B. & 13 & 25 \\
\hline Ci. & 20 & 30 \\
\hline D. & 5 & I 5 \\
\hline
\end{tabular}

etc.

Many of the new cases are early, and hence amenable to rapid cure. They thus become valuable advertisements for our campaign. In some villages, presentation for regular treatment by the local cases has become a matter of community interest, and it is commonly our experience that the healthy villagers become copartners in the great enterprise of eradicating leprosy from their district. Ostracism has become much less, and we now sometimes get interested villagers looking on at the clinics.

\section{Conclusion}

We do not believe that the village meetings along will root out every case of leprosy. This can only result in course of time from the work of a full scale leprosy control scheme. But we do believe that our modest and improvised effort is yielding useful results in the form of increasing numbers of patients coming forward for treatment, and also in a more liberal attitude on the part of village communities to their own patients.

We suggest that a modest propaganda programme might with advantage be considered by small hospitals wishing to take up antileprosy work, as an interim method of reaching leprosy in the villages, until a full scale epidemiology programme can be started. 